\title{
Host plant adaptability and proteomic differences of diverse Rhopalosiphum maidis (Fitch) lineages
}

\author{
Jianqing Guo ${ }^{1,2,3}$ (๑) | Gang Hao ${ }^{1}$ | Séverin Hatt ${ }^{4}$ | \\ Zhenying Wang $^{2}$ | Frédéric Francis ${ }^{3}$
}

\begin{abstract}
${ }^{1}$ College of Agriculture and Forestry, Hebei North University, Zhangjiakou, Hebei, China

${ }^{2}$ State Key Laboratory for Biology of Plant Diseases and Insect Pests, Institute of Plant Protection, Chinese Academy of Agricultural Sciences, Beijing, China

${ }^{3}$ Functional and Evolutionary Entomology, Gembloux Agro-Bio Tech, University of Liège, Gembloux, Belgium

${ }^{4}$ Agroecology and Organic Farming, Institute of Crop Science and Resource Conservation, University of Bonn, Bonn, Germany
\end{abstract}

\section{Correspondence}

Zhenying Wang, Institute of Plant Protection, Chinese Academy of Agricultural Sciences,

No. 2 Yuanmingyuan West Road, Beijing 100193, China.

Email: zywang@ippcaas.cn

Frédéric Francis, Functional and Evolutionary Entomology, Gembloux Agro-Bio Tech, University of Liège, Passage des Déportés 2, B-5030 Gembloux, Belgium.

Email: frederic.francis@ulg.ac.be

\begin{abstract}
Corn leaf aphid Rhopalosiphum maidis (Fitch) can feed on various cereal crops and transmit viruses that may cause serious economic losses. To test the impact of both host plant species and age on $R$. maidis, as well as the proteomic difference of diverse populations, we first investigated the survival and reproduction of six R. maidis populations (i.e., LF, HF, GZ, DY, BJ, and MS) via a direct observation method in the laboratory on 10 and $50 \mathrm{~cm}$ high maize seedlings, and $10 \mathrm{~cm}$ high barley seedlings. Then a proteomic approach was implemented to identify the differentially expressed proteins from both aphids and endosymbionts of $\mathrm{BJ}$ and MS populations. Results indicated that the BJ population performed significantly better than the others on both barley and $50 \mathrm{~cm}$ high maize seedlings, while no population could survive on $10 \mathrm{~cm}$ high maize seedlings. The proteomic results demonstrated that the expression levels of myosin heavy chain (muscle isoform $\mathrm{X12}$ ) (spot 781) and peroxidase (spot 1383) were upregulated, while ATP-dependent protease Hsp 100 (spot 2137) from Hamiltonella defensa and protein SYMBAF (spot 2703) from Serratia symbiotica were downregulated in the $B J$ population when compared to expression levels of the MS population. We hypothesize that the fatalness observed on $10 \mathrm{~cm}$ high maize seedlings may be caused by secondary metabolites that are synthesized by the seedlings and the
\end{abstract}


MS population of $R$. maidis should be more stress-resistant than the BJ population. Our results also provide insights for understanding the interaction between host plants and aphids.

\section{KEYWORDS}

corn leaf aphid, plant age, plant species, population, proteome

\section{1 | INTRODUCTION}

Rhopalosiphum maidis (Fitch) (Hemiptera: Aphididae) is a severe sap-sucking pest on maize (Zea mays L.) that occurs globally (Foott \& Timmins, 1973; Tzin et al., 2015). This insect also attacks barley (Hordeum vulgare L.) and some other cereal crops such as sorghum (Sorghum bicolor L. Moench), oat (Avena sativa L.), and wheat (Triticum aestivum L.) (Carena \& Glogoza, 2004; Tabikha, 2016). In addition to physical damage on the host plant, R. maidis can also transmit viruses, including Maize dwarf mosaic virus and Barley yellow dwarf virus (Parry et al., 2012; Saksena et al., 1964; Thongmeearkom et al., 1976), which may lead to serious damages in maize production.

Aphids can survive on different cereal crops although some hosts may exhibit a certain degree of resistance. Previous studies on $R$. maidis showed different survival and reproductive rates on different host plants of barley and wheat (Hirano \& Ito, 1964; Singh \& Painter, 1964). Research on other aphid species also showed that Toxoptera citricida (Kirkaldy), for instance, developed at a slower rate on sour orange, Duncan grapefruit, and Mexican lime than on Carrizo and sweet orange (Tang et al., 1999), whereas Aphis craccivora (Koch) showed the best potential population growth on Vicia faba at $25^{\circ} \mathrm{C}$ compared to Trifolium subterraneum cultivars and Medicago minima (Berg, 1984). In this way, resistant host plants or genotypes can be determined to improve biological control efficacy (Narang \& Rana, 1999).

Different aphid populations can furthermore have various levels of success on the same host plant (Broeke et al., 2013), as previously reported for Acyrthosiphon pisum (Sandström \& Pettersson, 1994), Myzus persicae and A. craccivora (Edwards, 2001) and Sitobion avenae (Barrios-SanMartín et al., 2016), demonstrating that long-term population differentiation may endow different populations living in various environments with diverse biological characteristics.

Many aphids harbor secondary symbionts (i.e., facultative symbionts) in nature. Some aphids are single-infected while others are double- or multi-infected with different secondary symbionts (Guo et al., 2019; Weldon et al., 2019). These symbionts are primarily transmitted maternally (i.e., vertically transferred) within populations, or can exhibit horizontal transmission among species (Oliver et al., 2010). According to previous studies, secondary symbionts offer their host aphids benefits such as resistance to natural enemies and increasing the fitness of their host plants to persist and spread (Guo et al., 2017).

With this context in mind, the present study aimed at assessing the performance (i.e., longevity and reproduction) of different populations of an aphid species ( $R$. maidis) on host plants that differed in age and species. Six R. maidis populations were monitored on barley $(10 \mathrm{~cm}$ high), small maize seedlings $(10 \mathrm{~cm} \mathrm{high)}$ and high maize seedlings (50 cm high) under laboratory conditions. A proteomic approach, using twodimensional difference gel electrophoresis (2D-DIGE) analysis and mass spectrometry, was applied to provide insight into the putative molecular mechanisms (including symbiont infestation) underlying the potential variation of aphid performances. 


\section{2 | MATERIALS AND METHODS}

\subsection{Aphid lineages}

Six lineages of R. maidis, namely BJ, DY, GZ, HF, LF, and MS populations, were collected from maize field in Beijing, Dongyang, Guangzhou, Hefei, Langfang and Mangshi cities of China respectively in 2014 (Figure 1). All clones were reproduced initially from one female and then reared separately at $23 \pm 1^{\circ} \mathrm{C}$, L16: D8 photoperiod and $60 \%-80 \%$ relative humidity $(\mathrm{RH})$ in laboratory on barley seedlings for more than ten generations before test.

\subsection{Host plants}

Three treatments of host plants, barley seedlings $(10 \mathrm{~cm}$ high), small maize seedlings $(10 \mathrm{~cm}$ high) and high maize seedlings $(50 \mathrm{~cm}$ high), were used for this study. The height of the host plants was measured with a ruler. To ensure germination rate and uniformity, the maize seeds were treated with accelerating germination before sowing into the soil. Rearing conditions for plants were $20 \pm 1^{\circ} \mathrm{C}, 60 \%-80 \% \mathrm{RH}$ and a photoperiod of L16: D8 before inoculation of aphid. All plants were moved to aphid rearing conditions as described above after inoculation.

\section{3 | Treatment settings}

Both barley seeds and germinated maize seeds were sown in $10 \times 10 \mathrm{~cm}$ square plastic pots. We kept $12 \pm 1$ barley seedlings and one maize seedling in each pot. Five adult apterous aphids were inoculated to the seedlings of required height in each pot, then the pots were separated by a plastic tube $(10 \mathrm{~cm}$ in diameter) covered by gauze element. Each treatment was replicated 10 times and the total survival number of aphids was observed at the same time every day for 1 week. We recorded the survival number of inoculated adults and number of nymphs for 4 days since it was difficult to distinguish the inoculated adults from the fifth day.

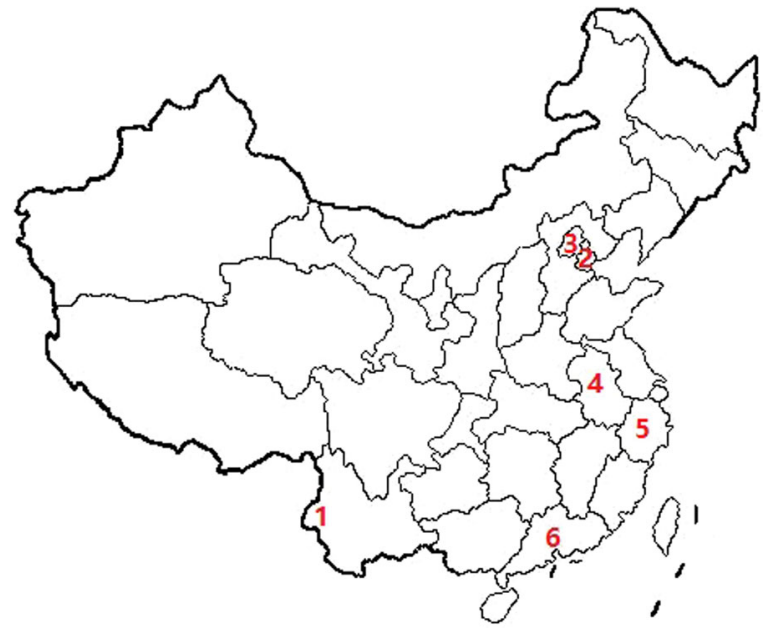

FIGURE 1 Collecting locations of six Rhopalosiphum maidis populations in China. 1, MS; 2, LF; 3, BJ; 4, HF; 5, DY; 6, GZ 


\section{4 | 2D-DIGE and protein identifications}

BJ and MS populations were selected to do proteomic analysis since BJ population performed the best while MS population was more abundant in endosymbionts according to our previous study (Guo et al., 2019). Total protein from around $50 \mathrm{mg}$ fresh $R$. maidis of $\mathrm{BJ}$ and MS populations were extracted, purified and quantified as described by Francis et al. (2010). Three Cy dyes (GE Healthcare) were used for labelling and protein samples of BJ and MS aphid clones were labelled either with $\mathrm{Cy} 3$ or $\mathrm{Cy} 5$ and mixed with an internal reference standard protein mixture (pooled from equal aliquots from all experimental samples) labelled with $\mathrm{Cy} 2$. Two replicates from each treatment with one dye (Cy3 or Cy5) and a third replicate with the other of the two Cy dyes were established for a conventional dye swap of DIGE. The first and second-dimensional electrophoresis, the excision of protein spots and the process of protein identification were performed following the description in Francis et al. (2010).

\section{5 | Statistical analysis}

Generalised linear mixed effect models (package "Ime4," function "glmer"; Bates et al., 2014)) with Poisson error distribution (log-link function) were fitted to test whether the abundance of aphids (i.e., the nymphs, the survived inoculated adults, and the total abundance of aphids) (i) differed between populations on each crop separately (i.e., populations analyzed as fixed factor), (ii) differed between host plants for each population separately (i.e., host plants as fixed factor). The observed plants (i.e., 10 repetitions per crop) were included as random effects as measurements were repeated each time on the same plant. For each model, the effect of the fix factor was tested using a likelihood-ratio test $(p<0.05)$ and means (i.e., between the different populations or between the different host plants) were compared using a post hoc test of Tukey ( $p<0.05$, package "multcomp," function "glht," Hothorn et al., 2008). The statistical analyses regarding the survival and reproduction of $R$. maidis were performed using $R$ program ( $R$ Core Team, 2013). For the proteomic analysis, the fold-change ratios were used to compare the expression levels of proteins between two populations. Only fold-change ratios with $p<0.05$ were statistically significant.

\section{3 | RESULTS}

\section{1 | Number of nymphs reproduced per female and survival of inoculated adults on different hosts plants}

Host plants had a significant effect on the abundance of aphid nymphs produced for all $R$. maidis populations (BJ: $\chi^{2}=88.6, d f=2, p<0.001$; DY: $\chi^{2}=38.8, d f=2, p<0.001 ; \mathrm{GZ}: \chi^{2}=40.2, d f=2, p<0.001 ; \mathrm{HF}: \chi^{2}=79.7, d f=2$, $p<0.001 ; \mathrm{LF}: \chi^{2}=43.1, d f=2, p<0.001$; MS: $\chi^{2}=58.2, d f=2, p<0.001$ ). Aside from the HF population, the number of nymphs for the other five populations was significantly higher on barley than on high maize $(p<0.05)$, and significantly higher (for all six populations) on high maize than on small maize $(p<0.05)$ (Figure 2). It was also found that the number of nymphs produced by each female per day on high maize reached maximum on the second or third day (for all populations), while the number was still increasing on the fourth day for five populations (except LF) when tested on barley. On small maize, less than or only one nymph was produced by each female per day for all six populations (Figure 2).

Host plants also had a significant effect on the survival of inoculated adults for $B J\left(x^{2}=18.2, d f=2, p<0.001\right)$, $\mathrm{GZ}\left(\chi^{2}=18.0, d f=2, p<0.001\right), \mathrm{HF}\left(\chi^{2}=33.1, d f=2, p<0.001\right)$, and $\mathrm{MS}\left(\chi^{2}=31.1, d f=2, p<0.001\right)$ populations but not for $\mathrm{DY}\left(\chi^{2}=1.9, d f=2, p=0.395\right)$ or $\operatorname{LF}\left(\chi^{2}=3.2, d f=2, p=0.201\right)$ populations. The survival number of adults was significantly higher on barley than on high maize and small maize $(p<0.05)$ with the exception of LF and DY 
(a)

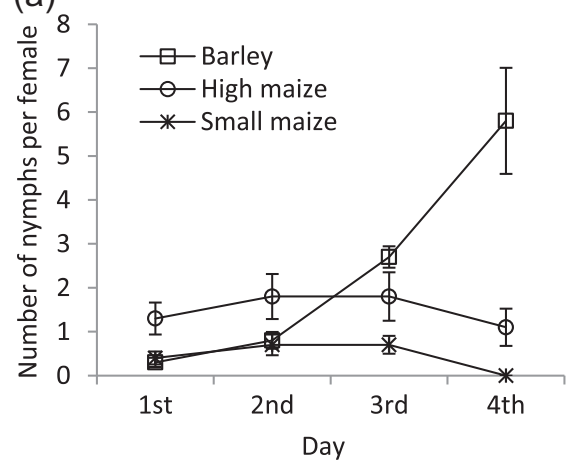

(c)

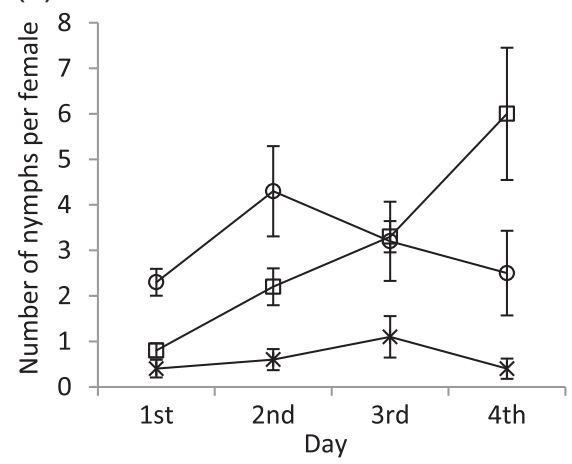

(e)

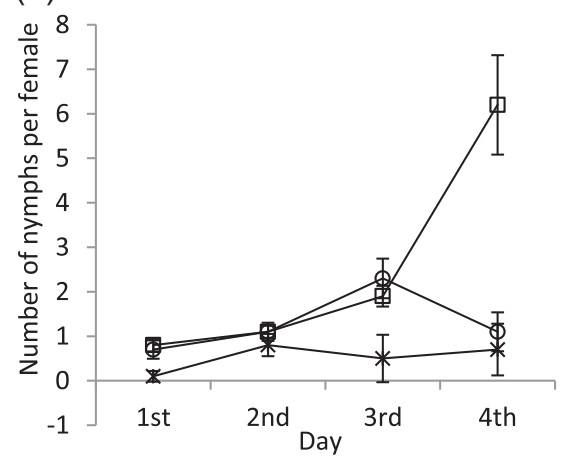

(b) 8

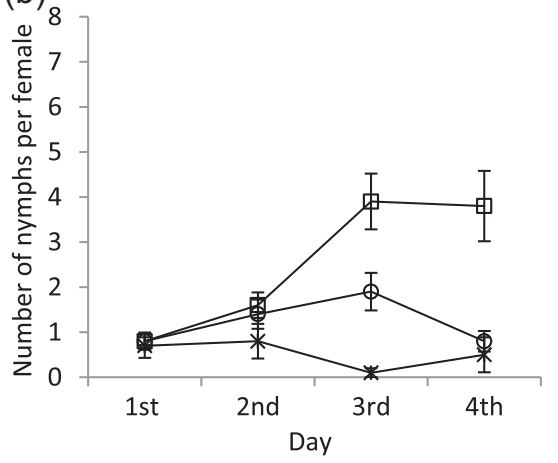

(d)

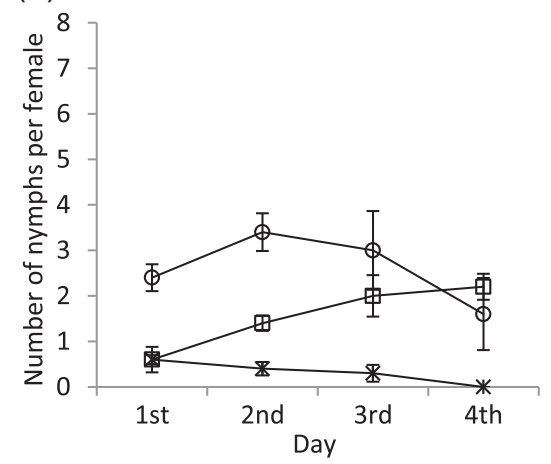

(f)

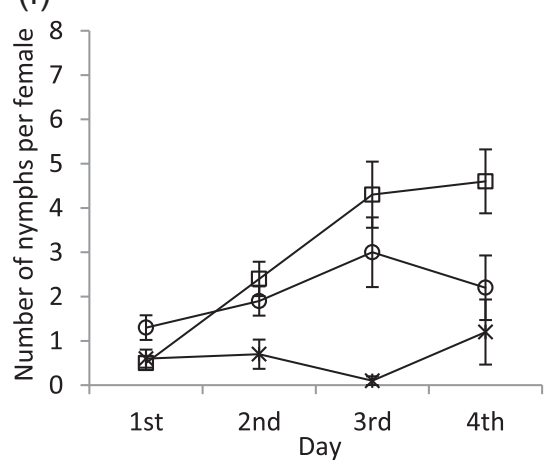

FIGURE 2 Number of nymphs produced by each female per day on different host plants of six R. maidis populations. (a), MS; (b), LF; (c), BJ; (d), HF; (e), DY; (f), GZ

populations. Aside from the MS population, for which the survival number of adults was significantly higher on small maize than on high maize $(p<0.05)$, there were no significant differences with regards to the adult survival for the other five populations (Figure S1).

\section{2 | Total aphid survival and reproduction on different plant hosts}

Host plants had a significant effect on the survival and reproduction of aphids for all populations (BJ: $\chi^{2}=3575.2$, $d f=2, p<0.001 ; \mathrm{DY}: \chi^{2}=1005.1, d f=2, p<0.001 ; \mathrm{GZ}: \chi^{2}=1907.4, d f=2, p<0.001 ; \mathrm{HF}: \chi^{2}=1922.5, d f=2$, 
$p<0.001 ;$ LF: $\left.\chi^{2}=1439.5, d f=2, p<0.001 ; \mathrm{MS}: \chi^{2}=2288.7, d f=2, p<0.001\right)$. The survival and reproduction of $R$. maidis populations on barley were significantly higher than on high maize $(p<0.001)$ (Figure S2) and the total survival numbers on high maize were significantly higher than that of small maize $(p<0.001)$ for all six lineages (Figure S3). Figure 3a shows that no clones were able to survive on small maize. Although several progeny nymphs were deposited in the first and second day, the total number of aphids decreased rapidly from the third to the seventh day. We observed that the nymphs were unable to grow and most of them died at the first or second instar.

Contrastingly, R. maidis populations could survive on high maize seedlings, although the aphid numbers increased significantly slower than on barley (especially from the fourth day onward) (Figure S2). By the seventh day

(a)

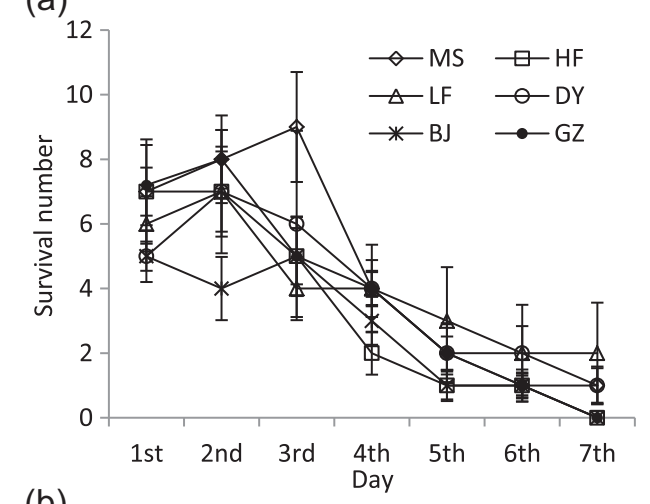

(b)

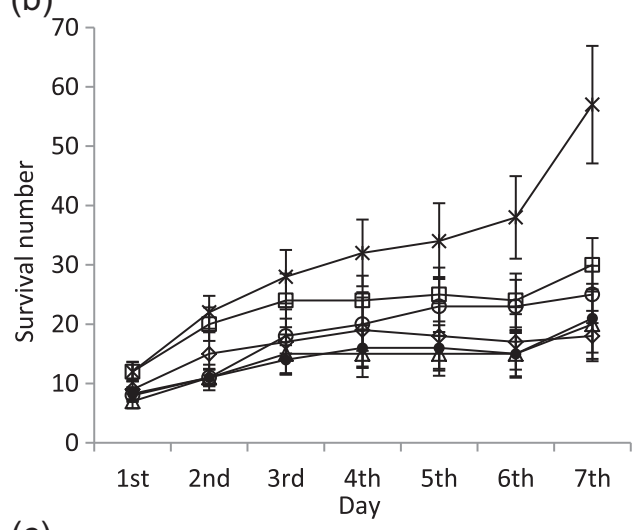

(c)

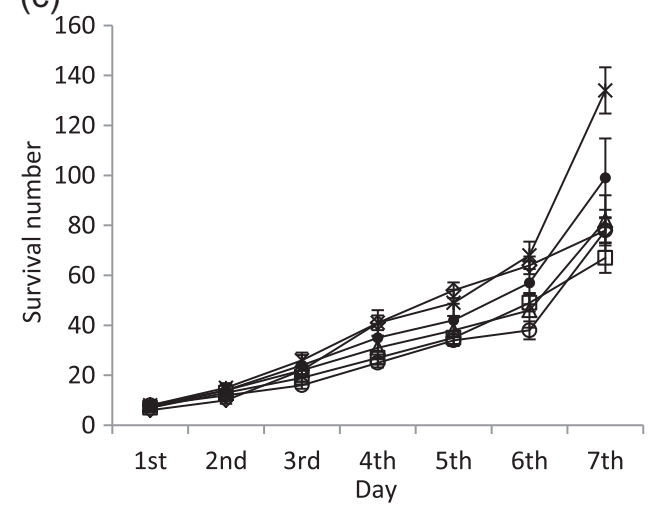

FIGURE 3 Survival number of six R. maidis populations on different host plants. (a), small maize; (b), high maize; (c), barley 
on high maize, the highest aphid number $(n=57)$ of the BJ population was about three times that of the lowest number $(n=18)$ of the MS population (Figure $3 b)$.

All R. maidis populations performed best on the barley seedlings (Figure 3c). Notably, the BJ population showed the fastest reproduction cycle with the number of aphids reaching 134 on the seventh day-nearly two times that of the number of MS and DY populations $(n=78)$. The HF population produced the lowest number of surviving aphids $(n=67)$ on barley by the seventh day.

The mean survival numbers per day were significantly different among populations for small maize $\left(\chi^{2}=43.48\right.$, $d f=5, p<0.001)$, high maize $\left(x^{2}=860.53, d f=5, p<0.001\right)$ as well as barley $\left(x^{2}=439.73, d f=5, p<0.001\right)$ (Figure S4). The mean numbers per day on small maize were no more than five (Figure S4a), while the mean number of the BJ population on high maize was significantly higher $(p<0.001)$ than that of the other five populations (Figure S4b). No difference was found $(p>0.1$ ) between LF and GZ populations (exhibiting the lowest mean survival numbers on high maize). With barley as the host plant, a significantly higher mean survival number of the BJ population was observed in comparison to the other five lineages $(p<0.001)$ (Figure S4c). There was no difference between the GZ and MS populations ( $p>0.1$ ), nor was there a significant difference between the HF and DY populations $(p>0.1)$ which were significantly lower in survival number than the other four populations $(p<0.05)$.

\section{3 | Identification of differentially expressed proteins}

In total, 466 proteins were identified from the 2D gel among which 77 protein spots varied significantly $(p<0.05)$ (Figure S5). The complete properties of over- and under-expressed proteins in the BJ population on MS population of $R$. maidis were listed in Tables 1 and 2 according to their relations to metabolic pathways in aphids and bacterial endosymbionts. We found that 57 proteins were related to aphids (Table 1) and 20 proteins were related to endosymbionts (Table 2). The fold change ratios of these proteins between the two $R$. maidis populations ranged from -1.9 to 1.8 (Tables 1 and 2). These differentially expressed proteins showed that 16/57 (Table 1) in the aphid group and 11/20 (Table 2) in the endosymbiont group were overexpressed in the BJ population versus the MS population. In particular, the amount of myosin heavy chain (muscle isoform X12) (spot number: 781) and peroxidase (spot number: 1383) from the aphid group in the BJ population was 1.7 and 1.6 times of that in the MS population respectively. However, the amount of bifunctional glutamate synthase subunit beta (spot number: 1664) in Rickettsia rickettsii from the endosymbiont group in the BJ population was -1.9 times that of the MS population. Also, the expression levels of ATP-dependent protease, Hsp 100 (spot number: 2137) from Hamiltonella defensa, and protein SYMBAF (spot number: 2703) from Serratia symbiotica were -1.4 and -1.5 times in the BJ versus MS population.

With regards to proteins in the aphid group, $86 \%$ were detected in A. pisum while fewer were detected in Aphis citricidus (5\%), Aphis glycines (2\%), Aphis laciniariae (2\%), Rhopalosiphum padi (3\%) and Schizaphis graminum (2\%), respectively (Figure 4a). With regards to the endosymbiont group, various proteins were detected in Buchnera aphidicola (10\%), H. defensa (5\%), Regiella insecticola (10\%), Rickettsia (40\%), S. symbiotica (5\%) and Spiroplasma (30\%) (Figure 4b).

The distribution of proteins with different expression levels in BJ and MS populations, as they relate to metabolic pathways, is shown in Figure 5. We found that proteins in the aphid group accounted for various roles in metabolic pathways such as cell function and structure (18\%), energy metabolism (12\%), folding, sorting and degradation (11\%), protein-protein interactions (11\%), and stress tolerance (11\%). On the other hand, proteins involved in metabolic pathways of carbohydrate metabolism (15\%), energy metabolism (10\%), signaling molecules (10\%), and interaction, replication and repair (35\%) were prominent in the endosymbiont group.

In the aphid group, $7 / 10$ proteins that take part in metabolic pathways of cell function and structure were upregulated, while 6/7 proteins that participate in energy metabolism, 5/6 proteins that participate in folding, sorting and degradation, $5 / 6$ proteins that participate in stress tolerance and all six proteins that participate in 


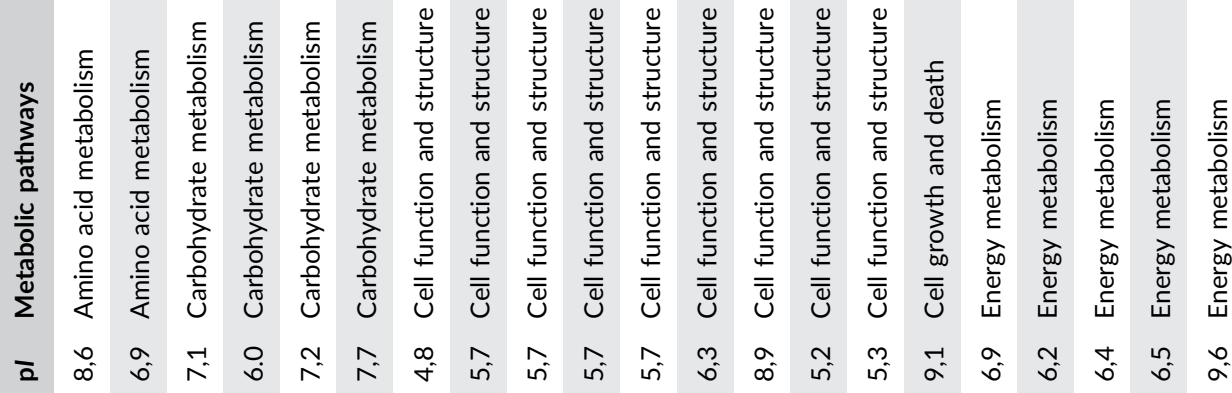

竞

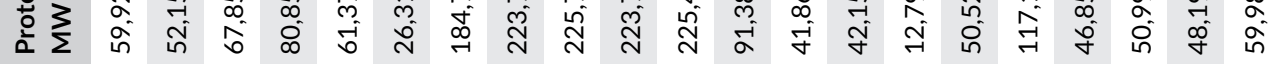

$\circ$

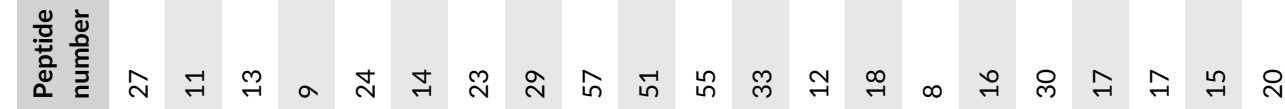
$\sum \sum_{\substack{0 \\ \frac{\pi}{0}}}^{n}$ $\frac{5}{\sigma}$

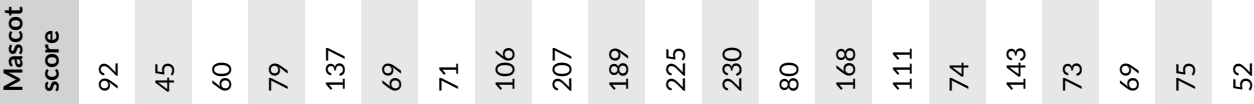
$\stackrel{+}{\frac{\pi}{5}}$ $\frac{n}{\frac{0}{c}}$

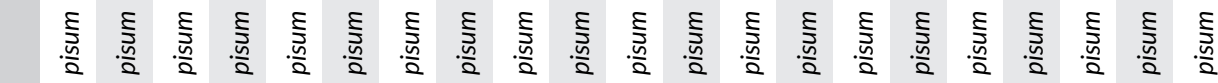

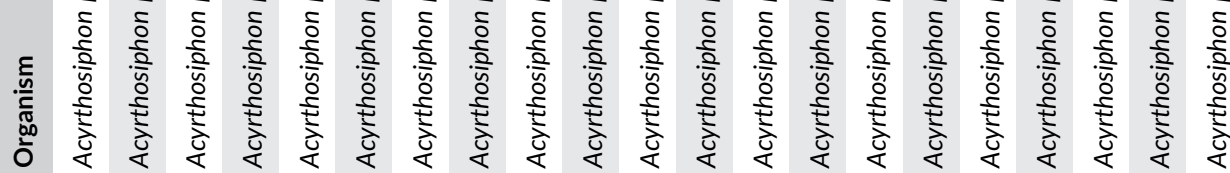

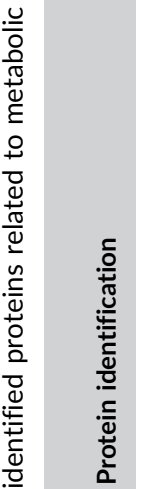

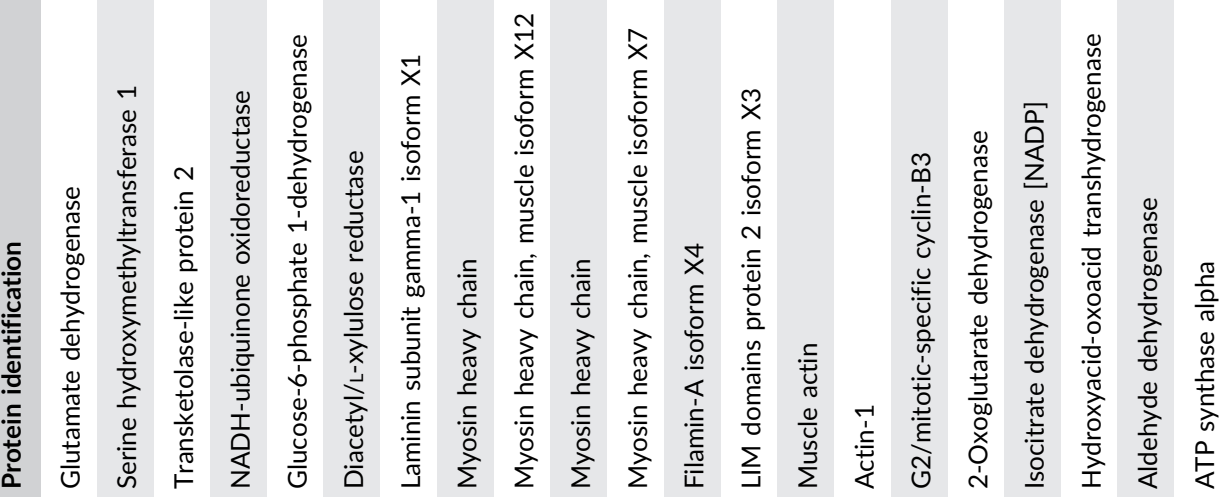
$\stackrel{\underline{\underline{n}}}{4}$

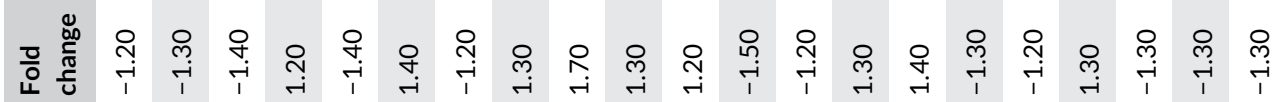

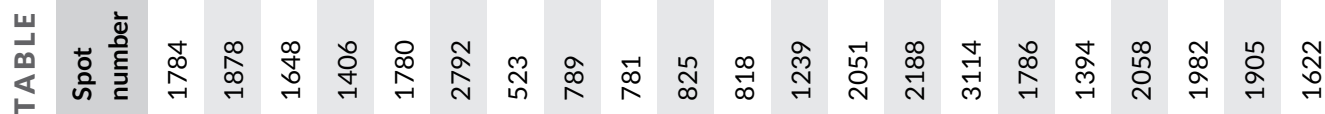




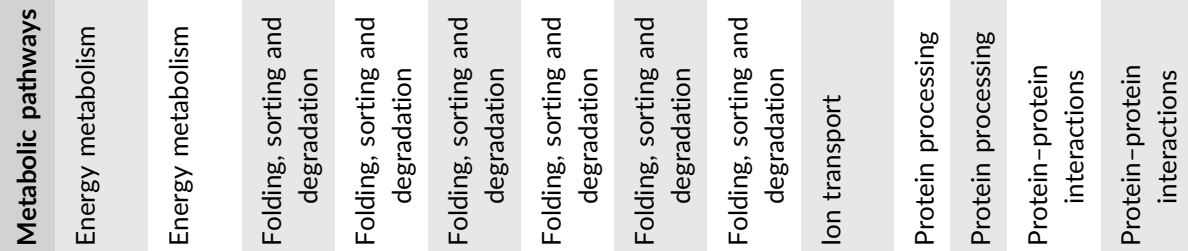

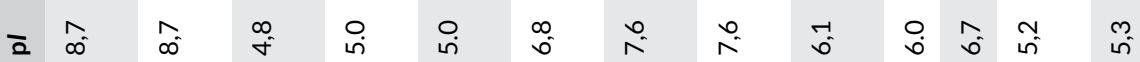

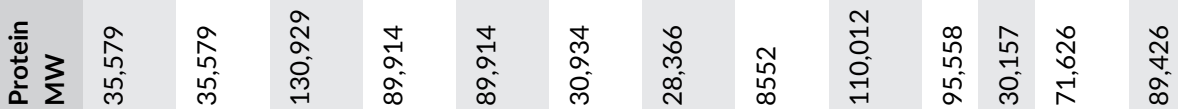

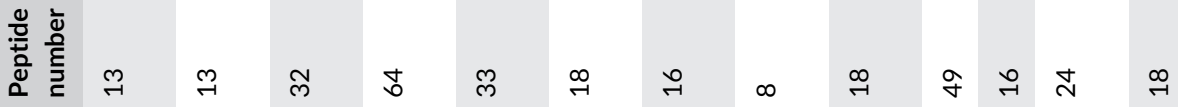

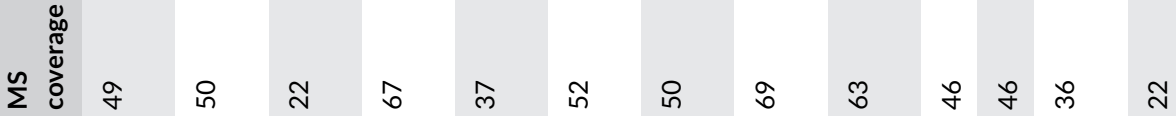

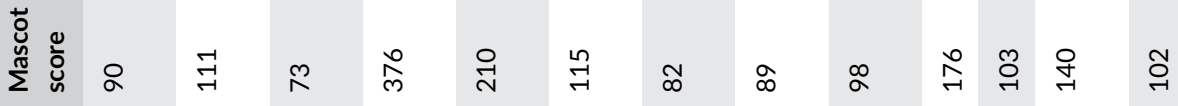

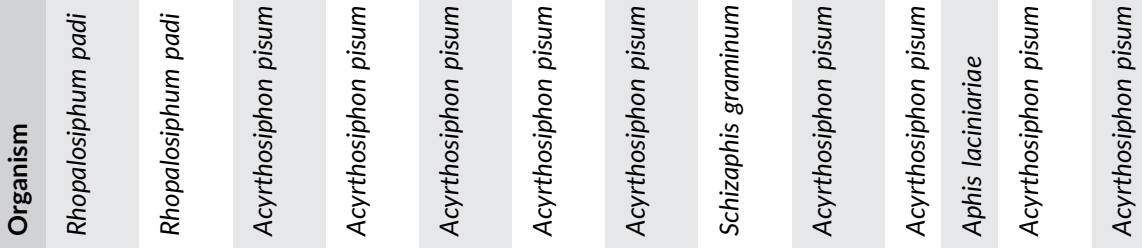

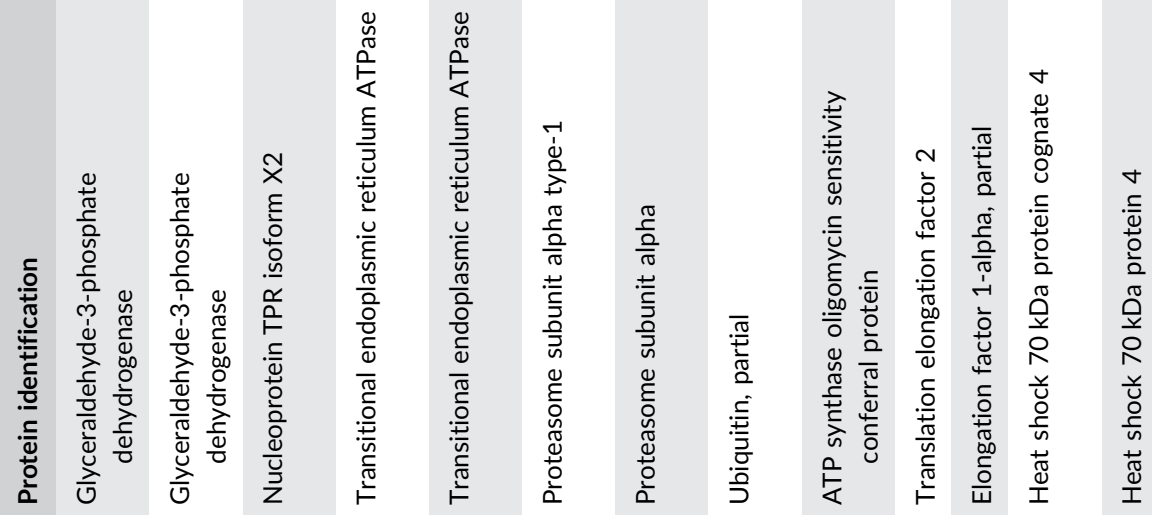

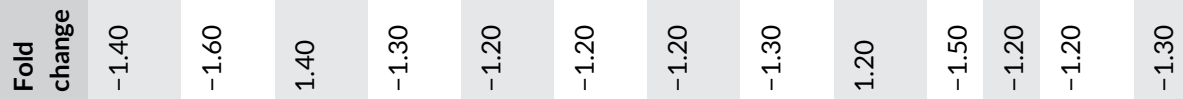

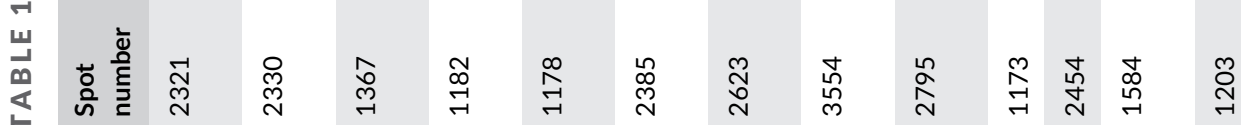




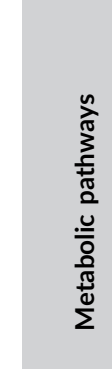

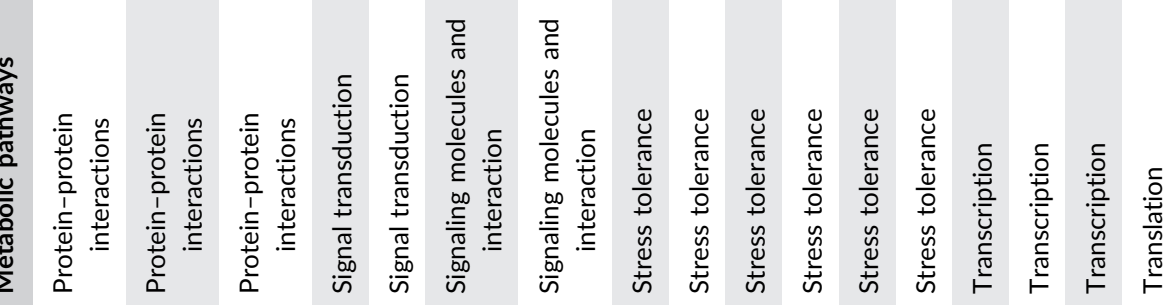

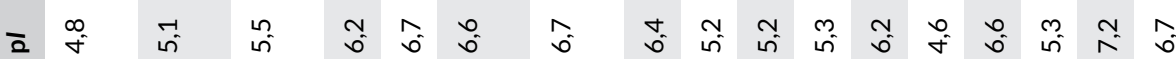

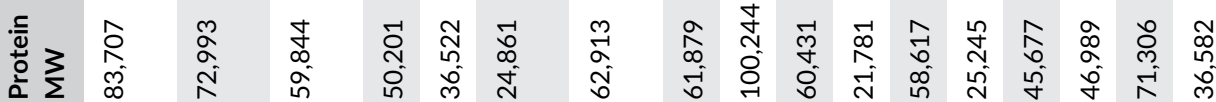

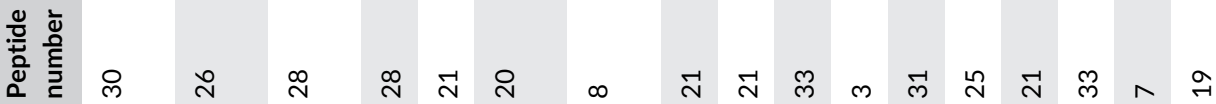

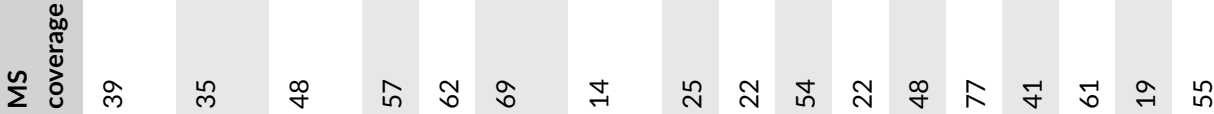

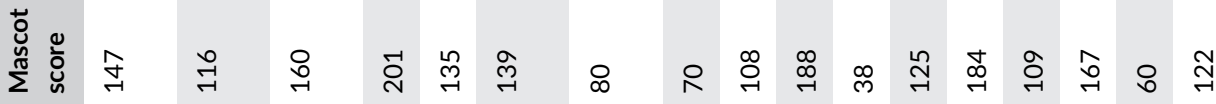

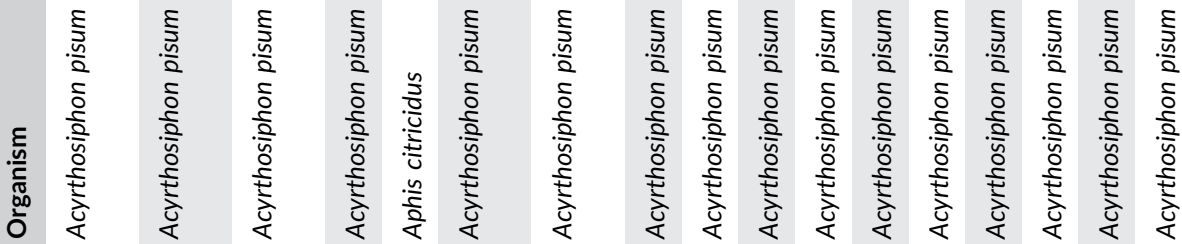

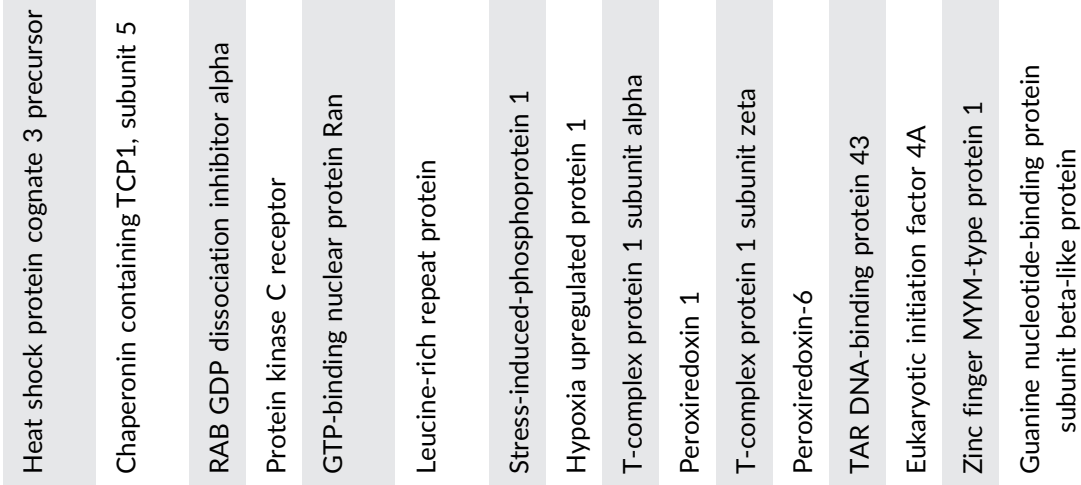

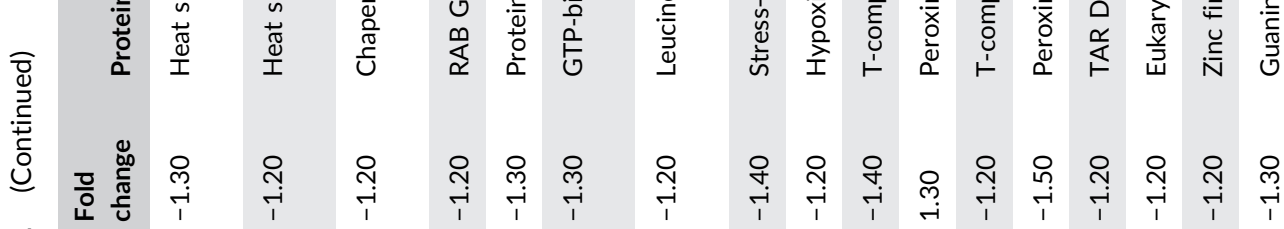

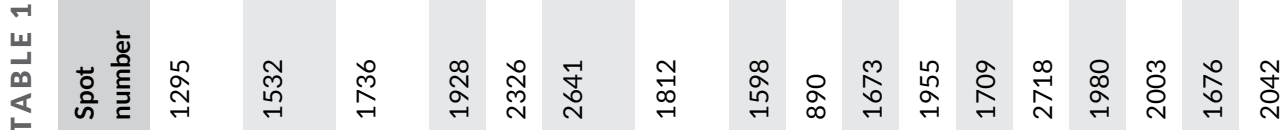




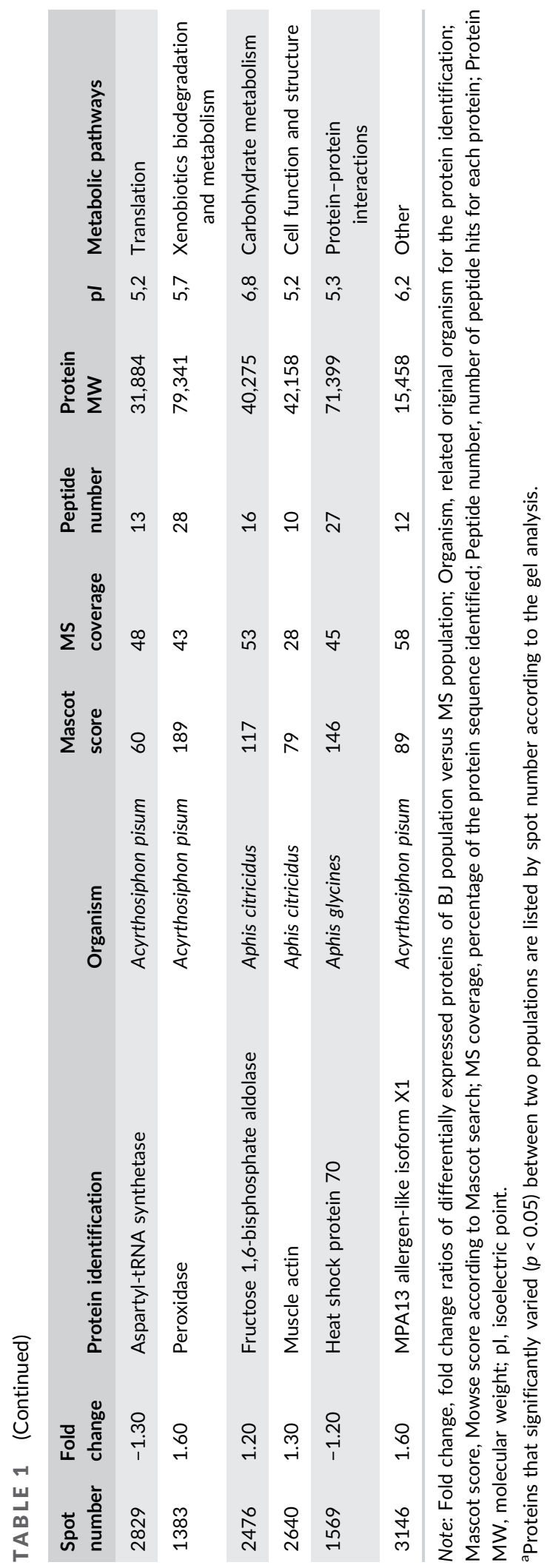




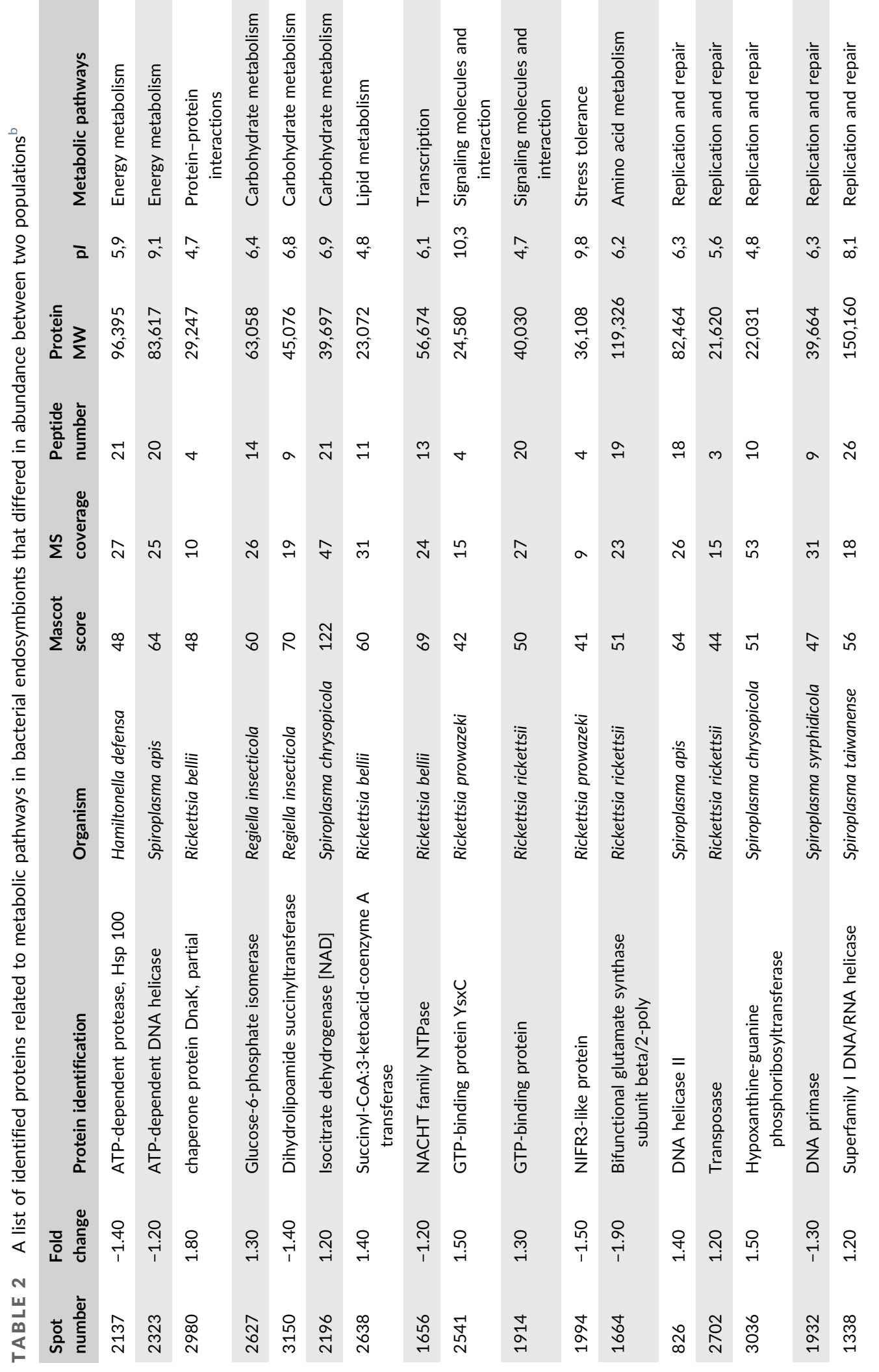




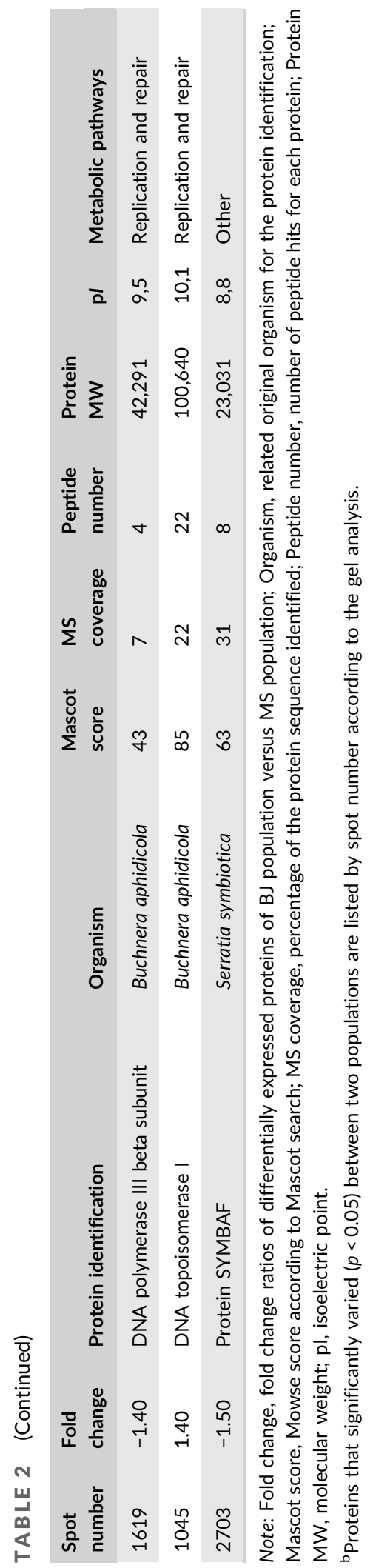


(a)

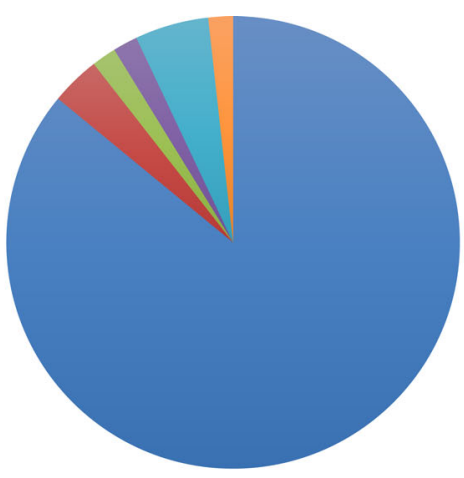

घcyrthosiphon pisum $\backsim$ Rhopalosiphum padi $\backsim$ Schizaphis graminum

Aphis laciniariae $\quad$ Aphis citricidus $\quad$ Aphis glycines

(b)

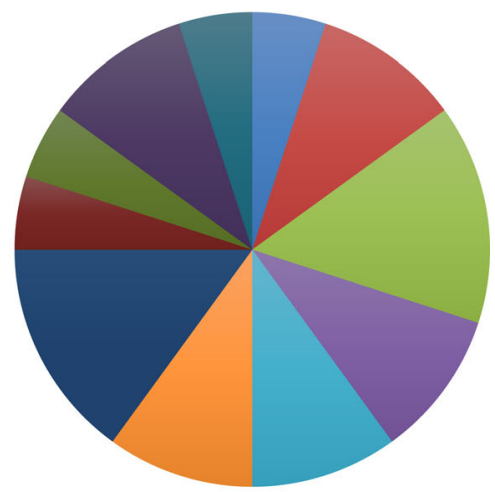

$\begin{array}{lll}\square \text { Hamiltonella defensa } & \text { Spiroplasma apis } & \text { Rickettsia bellii } \\ \square \text { Regiella insecticola } & \text { Spiroplasma chrysopicola } \square \text { Rickettsia prowazeki } \\ \square \text { Rickettsia rickettsii } & \text { Spiroplasma syrphidicola } \square \text { Spiroplasma taiwanense } \\ \square \text { Buchnera aphidicola } & \text { Serratia symbiotica }\end{array}$

FIGURE 4 Distribution of organisms for proteins with different expression levels in R. maidis of BJ and MS populations. (a) proteins related to aphids, (b) proteins related to endosymbionts

protein-protein interactions were downregulated in the BJ population compared to that of the MS population (Table 1). Similarly, all proteins involved in energy metabolism and stress tolerance in the endosymbiont group were downregulated in the BJ population (Table 2), whereas $5 / 7$ proteins that participate in replication and repair were upregulated (Table 2).

\section{4 | DISCUSSION}

Rhopalosiphum maidis is known to be one of the major pests of maize in the field. Our laboratory data indicated that although all six aphid populations best performed on barley seedlings, they showed a suboptimal reproductive potential on $50 \mathrm{~cm}$ high maize seedlings. As previously reported (Hirano \& Ito, 1964), the survival rates of $R$. maidis were different between barley and wheat hosts, and performed differently between different wheat ages. 
(a)

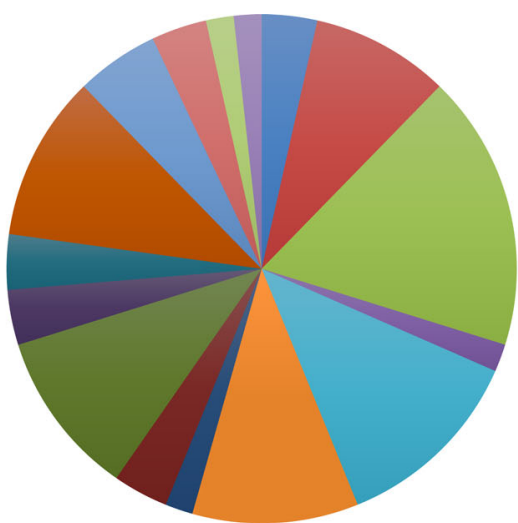

\begin{tabular}{|c|c|}
\hline Amino acid metabolism & Carbohydrate metabolism \\
\hline Cell function and structure & Cell growth and death \\
\hline Energy metabolism & Folding, sorting and degradation \\
\hline Ion transport & Protein processing \\
\hline Protein-protein interactions & - Signal transduction \\
\hline Signaling molecules and interaction & Etress tolerance \\
\hline Transcription & - Translation \\
\hline Xenobiotics biodegradation and metabolism & Other \\
\hline
\end{tabular}

(b)

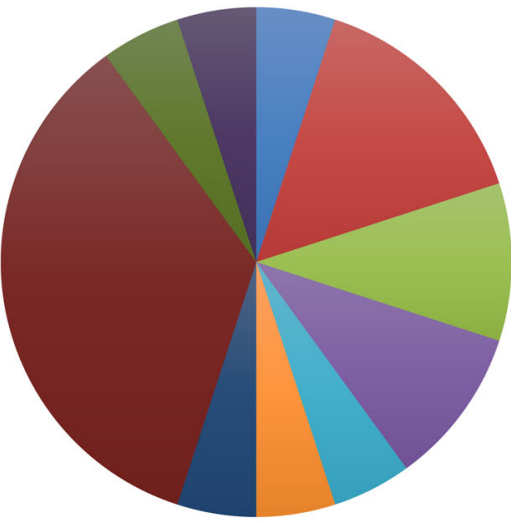

Amino acid metabolism
Energy metabolism
Stress tolerance
- Protein-protein interactions
- Lipid metabolism

- Carbohydrate metabolism

- Signaling molecules and interaction

- Transcription

- Replication and repair

ather

FIGURE 5 Distribution of related metabolic pathways for proteins with different expression levels in R. maidis of $\mathrm{BJ}$ and MS populations. (a) proteins related to metabolic pathways in aphids, (b) proteins related to metabolic pathways in bacterial endosymbionts

In the present study, $10 \mathrm{~cm}$ high maize seedlings proved fatal to all $R$. maidis populations. We hypothesize that it was due to potential detrimental chemicals in young maize seedlings $(10 \mathrm{~cm}$ high) such as DIMBOA (2,4-dihydroxy-7-methoxy-1,4-benzoxazin-3-one). As a secondary metabolite (and hydroxamic acid) in many cereals, DIMBOA plays an important role in insect resistance (Klun et al., 1967; Pérez \& Niemeyer, 1989; Yan et al., 1995). Moreover, the concentration of DIMBOA varies according to plant organ and age (Cambier 
et al., 2000), research has shown that DIMBOA is synthesized concurrently with germination in maize and that the concentration reaches its highest level 24-36 h after germination (Ebisui et al., 2000). It has furthermore been reported that the concentration of DIMBOA decreases during subsequent plant growth and, in the aerial parts of maize, can drop to almost zero by the 20th day after germination (Cambier et al., 2000). In our study, R. maidis populations were introduced 4-5 days after host plant germination for the $10 \mathrm{~cm}$ high maize seedling treatment, with the expectation that biosynthesis of DIMBOA should still be ongoing (Cambier et al., 2000). Contrastingly, the inoculation of $R$. maidis populations was performed 19-20 days after germination for maize seedlings that were $50 \mathrm{~cm}$ in height (expecting that there would be almost no DIMBOA left in aerial parts at this time; Cambier et al., 2000). In addition, the barley seeds used in this study were from a cultivar that is unable to biosynthesize DIMBOA due to the elimination of the necessary benzoxazinone genes (Nomura et al., 2003). Future research is however required to confirm the resistance effect of DIMBOA in small maize seedlings.

Previous research found that the performance of different populations of A. craccivora was significantly different on faba bean, field pea as well as narrow-leafed lupin (Edwards, 2001). Also, when highly resistant wheat seedlings were used as host plants, the population growth rate of one S. avenae superclone was significantly higher than that of nonsuperclones (Barrios-SanMartín et al., 2016). Moreover, different genotypes of S. avenae identified through microsatellite analysis performed diversely on Poaceae (Figueroa et al., 2004). In this study, the total survival numbers of all $R$. maidis populations on high maize were significantly higher than on small maize (Figure S3). However, no significant difference in adult survival was detected between high and small maize for five of the populations (Figure S1), demonstrating that the adults were more adaptive to the detrimental chemicals in small maize than the nymphs. There was, however, also a significant decline in adult fecundity (Figure 2). The BJ population showed the best performance on both high maize and barley, and its mean survival number per day was also significantly higher than that of the other populations, suggesting that the BJ population was more adaptable and fertile. The aphid number of other populations slowly increased on $50 \mathrm{~cm}$ high maize seedlings (when compared with the BJ population), especially after the fourth day. The total number of the MS population even declined upon comparison of the seventh day to the fourth day. Nikolakakis et al. (2003) found a significant effect of "region/host plant origin" based on the different performances of various M. persicae clones. The six populations of $R$. maidis in the present study that collected from different regions of the same plant (maize) were tested, however, the effect of "host plant origin" should be tested in future research.

According to protein identification results, both myosin heavy chain, muscle isoform X12 (spot number: 781), and peroxidase (spot number: 1383) were overexpressed in the BJ population. Myosin heavy chain, muscle isoform X12 is involved in cell structure and function (Table 1) and it has been reported that myosin heavy chains could activate ATPase and be responsible for mechanochemical energy transduction (Kiehart et al., 1989). Additionally, peroxidase takes part in the pathway of xenobiotics biodegradation and metabolism (Table 1), and it has previously been shown that suppression of a peroxidase gene could reduce the survival rate in S. avenae (Fei et al., 2016). Based on this, these two proteins might thus be beneficial to the BJ population-allowing for stronger vitality and faster reproduction.

Conversely, both ATP-dependent protease, Hsp 100 (spot number: 2137) and protein SYMBAF (spot number: 2703) were overexpressed in the MS population. We infer that these proteins may be involved in heat shock resistance since both $H$. defensa (the organism of ATP-dependent protease, Hsp 100) and S. symbiotica (the organism of protein SYMBAF) have been reported to enhance the heat shock resistance for their host aphid (Russell \& Moran, 2006). Furthermore, the MS population was collected from Mangshi City $\left(24^{\circ} 26^{\prime} \mathrm{N}, 9^{\circ} 35^{\prime} \mathrm{E}\right)$, Yunnan Province where the average temperature is higher than that of Beijing City $\left(40^{\circ} 2^{\prime} \mathrm{N}, 116^{\circ} 16^{\prime} \mathrm{E}\right)$ which served as the collection site of the BJ population.

Secondary symbionts have been suggested to enact various effects on their host aphids such as host plant fitness, heat shock resistance, parasitoids resistance, longevity, and fecundity (Oliver et al., 2005; Russell \& Moran, 2006; Tsuchida et al., 2011; Vorburger et al., 2013). Both BJ and MS populations were infected with various secondary symbionts while Rickettsia and Spiroplasma exhibited a relatively high frequency of infection in these two 
populations of R. maidis, supporting previous findings (Guo et al., 2019). Nevertheless, the fold change ratios of all differentially expressed proteins were no more than twofold since both BJ and MS populations were originally collected from maize and reared under the same conditions.

In conclusion, the $\mathrm{BJ}$ population of $R$. maidis performed the best, both on high maize and barley seedlings, while maize seedlings in $10 \mathrm{~cm}$ height were fatal to all populations. Secondary metabolites may be responsible for the unfitness of small maize seedlings, but this hypothesis requires further verification. Proteomic analyzes showed that proteins involved in stress tolerance and energy metabolism were mostly downregulated in the BJ population (in both aphid and endosymbiont groups), indicating that the MS population might be more stress-resistant (especially to heat-shock) than the BJ population-even though the BJ population of $R$. maidis showed a faster reproduction rate.

\section{ACKNOWLEDGEMENTS}

This research was funded by the Young Talent Program of Hebei Higher Education (BJ2018009). We thank the University of Liège-Gembloux Agro-Bio Tech for supporting the experiment that made this paper possible.

\section{CONFLICT OF INTERESTS}

The authors declare that there are no conflict of interests.

\section{AUTHOR CONTRIBUTION}

Jianqing Guo: writing-review \& editing (equal).

\section{ORCID}

Jianqing Guo (D) http://orcid.org/0000-0002-2903-6563

\section{REFERENCES}

Barrios-SanMartín, J., Figueroa, C. C., \& Ramírez, C. C. (2016). Evidence of plastic probing behavior in a 'superclone' of the grain aphid Sitobion avenae. Bulletin of Entomological Research, 106, 801-808. https://doi.org/10.1017/S0007485 316000754

Bates, D., Maechler, M., Bolker, B. M., \& Walker, S. (2014). Ime4: Linear mixed-effects models using Eigen and S4. R package.

Berg, G. N. (1984). The effect of temperature and host species on the population growth potential of the cowpea aphid, Aphis craccivora Koch (Homoptera: Aphididae). Australian Journal of Zoology, 32, 345-352. https://doi.org/10.1071/ zo9840345

Broeke, C. J. M. T., Dicke, M., \& Loon, J. J. A. V. (2013). Feeding behaviour and performance of different populations of the black currant-lettuce aphid, Nasonovia ribisnigri, on resistant and susceptible lettuce. Entomologia Experimentalis et Applicata, 148, 130-141. https://doi.org/10.1111/eea.12084

Cambier, V., Hance, T., \& de Hoffmann, E. (2000). Variation of DIMBOA and related compounds content in relation to the age and plant organ in maize. Phytochemistry, 53, 223-229. https://doi.org/10.1016/S0031-9422(99)00498-7

Carena, M. J., \& Glogoza, P. (2004). Resistance of maize to the corn leaf aphid: A review. Maydica, 49, $241-254$.

Core Team, R. (2013). R: A language and environment for statistical computing. Vienna, Austria: R Foundation for Statistical Computing.

Ebisui, K., Ishihara, A., Hirai, N., \& Iwamura, H. (2000). Occurrence of 2,4-dihydroxy-7-methoxy-1,4-benzoxazin-3-one (DIMBOA) and a $\beta$-glucosidase specific for its glucoside in maize seedlings. Zeitschrift für Naturforschung $C, 53$, 793-798. https://doi.org/10.1515/znc-1998-9-1003

Edwards, O. R. (2001). Interspecific and intraspecific variation in the performance of three pest aphid species on five grain legume hosts. Entomologia Experimentalis et Applicata, 100, 21-30. https://doi.org/10.1046/j.1570-7458.2001. 00844.x

Fei, D., He, Q., \& Zhao, Z. (2016). Suppressing a peroxidase gene reduces survival in the wheat aphid sitobion avenae. Archives of Insect Biochemistry and Physiology, 93, 86-95. https://doi.org/10.1002/arch.21343

Figueroa, C. C., Simon, J. C., Gallic, J. F. L., Prunier-Leterme, N., Briones, L. M., Dedryver, C. A., \& Niemeyer, H. M. (2004). Effect of host defense chemicals on clonal distribution and performance of different genotypes of the cereal aphid Sitobion avenae. Journal of Chemical Ecology, 30, 2515-2525. https://doi.org/10.1007/s10886-004-7947-x 
Foott, W. H., \& Timmins, P. R. (1973). Effects of infestations by the corn leaf aphid, Rhopalosiphum maidis (Homoptera: Aphididae), on field corn in southwestern Ontario. The Canadian Entomologist, 105, 449-458. https://doi.org/10. 4039/Ent105449-3

Francis, F., Guillonneau, F., Leprince, P., Pauw, E. D., Haubruge, E., Jia, L., \& Goggin, F. L. (2010). Tritrophic interactions among Macrosiphum euphorbiae aphids, their host plants and endosymbionts: Investigation by a proteomic approach. Journal of Insect Physiology, 56, 575-585. https://doi.org/10.1016/j.jinsphys.2009.12.001

Guo, J. Q., Hatt, S., He, K. L., Chen, J. L., Francis, F., \& Wang, Z. Y. (2017). Nine facultative endosymbionts in aphids. A review. Journal of Asia-Pacific Entomology, 20, 794-801. https://doi.org/10.1016/j.aspen.2017.03.025

Guo, J. Q., Liu, X. W., Poncelet, N., He, K. L., Francis, F., \& Wang, Z. Y. (2019). Detection and geographic distribution of seven facultative endosymbionts in two Rhopalosiphum aphid species. MicrobiologyOpen, 8(8):e817. https://doi.org/ 10.1002/mbo3.817

Hirano, C., Ito Y. (1964). Effect of plant age on survival and reproduction of Rhopalosiphum maidis Fitch (Homoptera: Aphididae). Japanese Journal of Applied Entomology \& Zoology, 8, 317-323. https://doi.org/10.1303/jjaez.8.317

Hothorn, T., Bretz, F., \& Westfall, P. (2008). Simultaneous inference in general parametric models. Biometrical Journal: Journal of Mathematical Methods in Biosciences, 50, 346-363. https://doi.org/10.1002/bimj.200810425

Kiehart, D. P., Lutz, M. S., Chan, D., Ketchum, A. S., Laymon, R. A., Nguyen, B., \& Goldstein, L. S. B. (1989). Identification of the gene for fly non-muscle myosin heavy chain: Drosophila myosin heavy chains are encoded by a gene family. The EMBO Journal, 8(3), 913-922. https://doi.org/10.1002/j.1460-2075.1989.tb03452.x

Klun, J. A., Tipton, C. L., \& Brindley, T. A. (1967). 2,4-Dihydroxy-7-methoxy-I,4-benzoxazin-3-one (DIMBOA), an active agent in the resistance of maize to the European Corn Borer. Journal of Economic Entomology, 60, 1529-1533. https:// doi.org/10.1093/jee/60.6.1529

Narang, S., Rana, J. S. (1999). Screening of barley genotypes against corn leaf aphid, Rhopalosiphum maidis (Fitch.). Cereal Research Communications, 27, 131-138. https://doi.org/10.1007/BF03543929

Nikolakakis, N., Margaritopoulos, J. T., \& Tsitsipis, J. A. (2003). Performance of Myzus persicae (Hemiptera: Aphididae) clones on different host-plants and their host preference. Bulletin of Entomological Research, 93, 235-242. https://doi. org/10.1079/BER2003230

Nomura, T., Ishihara, A., Imaishi, H., Ohkawa, H., Endo, T. R., \& Iwamura, H. (2003). Rearrangement of the genes for the biosynthesis of benzoxazinones in the evolution of Triticeae species. Planta, 217, 776-782. https://doi.org/10.1007/ s00425-003-1040-5

Oliver, K. M., Degnan, P. H., Burke, G. R., \& Moran, N. A. (2010). Facultative symbionts in aphids and the horizontal transfer of ecologically important traits. Annual Review of Entomology, 55, 247-266. https://doi.org/10.1146/annurev-ento112408-085305

Oliver, K. M., Moran, N. A., \& Hunter, M. S. (2005). Variation in resistance to parasitism in aphids is due to symbionts not host genotype. Proceedings of the National Academy of Sciences of the United States of America, 102, 12795-12800. https://doi.org/10.1073/pnas.0506131102

Parry, H. R., Macfadyen, S., \& Kriticos, D. J. (2012). The geographical distribution of Yellow dwarf viruses and their aphid vectors in Australian grasslands and wheat. Australasian Plant Pathology, 41, 375-387. https://doi.org/10.1007/ s13313-012-0133-7

Pérez, F. J., \& Niemeyer, H. M. (1989). Reaction of DIMBOA, a resistance factor from cereals, with papain. Phytochemistry, 28, 1597-1600. https://doi.org/10.1016/S0031-9422(00)97806-3

Russell, J. A., \& Moran, N. A. (2006). Costs and benefits of symbiont infection in aphids: Variation among symbionts and across temperatures. Proceedings of the Royal Society B: Biological Sciences, 273, 603-610. https://doi.org/10.1098/ rspb.2005.3348

Saksena, K. N., Singh, S. R., Sill Jr., W. H. (1964). Transmission of barley Yellow-dwarf virus by four biotypes of the corn leaf aphid, Rhopalosiphum maidis. Journal of Economic Entomology, 57, 569-571. https://doi.org/10.1093/jee/57.4.569

Sandström, J., \& Pettersson, J. (1994). Amino acid composition of phloem sap and the relation to intraspecific variation in pea aphid (Acyrthosiphon pisum) performance. Journal of Insect Physiology, 40, 947-955. https://doi.org/10.1016/ 0022-1910(94)90133-3

Singh, S. R., \& Painter, R. H. (1964). Effect of temperature and host plants on progeny production of four biotypes of corn leaf aphid, Rhopalosiphum maidis. Journal of Economic Entomology, 57, 348-350. https://doi.org/10.1093/jee/57. 3.348

Tabikha, R. M. (2016). Impacts of temporal and spatial climatic changes on annual generations of Rhopalosiphum maidis and R. padi (Hemiptera: Aphididae) in Egypt, using Geographical Information System (GIS). Journal of Agricultural Informatics, 7, 13-22. https://doi.org/10.17700/jai.2016.7.1.249

Tang, Y. Q., Lapointe, S. L., Brown, L. G., Hunter, W. B. (1999). Effects of host plant and temperature on the biology of Toxoptera citricida (Homoptera: Aphididae). Environmental Entomology, 92, 895-900. https://doi.org/10.1093/ee/28. 5.895 
Thongmeearkom, P., Ford, R. E., \& Jedlinski, H. (1976). Aphid transmission of maize dwarf mosaic virus strains. Phytopathology, 66, 332-335. https://doi.org/10.1094/Phyto-66-332

Tsuchida, T., Koga, R., Matsumoto, S., \& Fukatsu, T. (2011). Interspecific symbiont transfection confers a novel ecological trait to the recipient insect. Biology Letters, 7, 245-248. https://doi.org/10.1098/rsbl.2010.0699

Tzin, V., Fernandez-Pozo, N., Richter, A., Schmelz, E. A., Schoettner, M., Schäfer, M., Ahern, K. R., Meihls, L. N., Kaur, H., Huffaker, A., Mori, N., Degenhardt, J., Mueller, L. A., \& Jander, G. (2015). Dynamic maize responses to aphid feeding are revealed by a time series of transcriptomic and metabolomic assays. Plant Physiology, 169, 1727-1743. https:// doi.org/10.1104/pp.15.01039

Vorburger, C., Ganesanandamoorthy, P., \& Kwiatkowski, M. (2013). Comparing constitutive and induced costs of symbiontconferred resistance to parasitoids in aphids. Ecology \& Evolution, 3, 706-713. https://doi.org/10.1002/ece3.491

Weldon, S. R., Russell, J. A., \& Oliver, K. M. (2019). More is not always better: Coinfections with defensive symbionts generate highly variable outcomes. Applied and Environmental Microbiology, 86, e02537-19. https://doi.org/10.1128/ AEM.02537-19

Yan, F., Xu, C., Li, S., Lin, C., Li, J. (1995). Effects of DIMBOA on several enzymatic systems in Asian corn borer, Ostrinia furnacalis (Guenée). Journal of Chemical Ecology, 21, 2047-2056. https://doi.org/10.1007/BF02033861

\section{SUPPORTING INFORMATION}

Additional supporting information may be found in the online version of the article at the publisher's website.

How to cite this article: Guo, J., Hao, G., Hatt, S., Wang, Z., \& Francis, F. (2022). Host plant adaptability and proteomic differences of diverse Rhopalosiphum maidis (Fitch) lineages. Archives of Insect Biochemistry and Physiology, 109, e21853. https://doi.org/10.1002/arch.21853 